\title{
PLAN VERDE PARA UNA CIUDAD PATRIMONIO DE LA HUMANIDAD. SEGOVIA
}

\author{
(GREEN PLAN FOR A MANKIND HERITAGE TOWN. SEGOVIA)
}

Arroyo, F.; Esteban, V.; Marcos, M. y Yoldi, L. Área de Urbanismo, Obras y Servicios. Ayuntamiento de Segovia ESPAÑA

Fecha de recepción: 27-XII-99

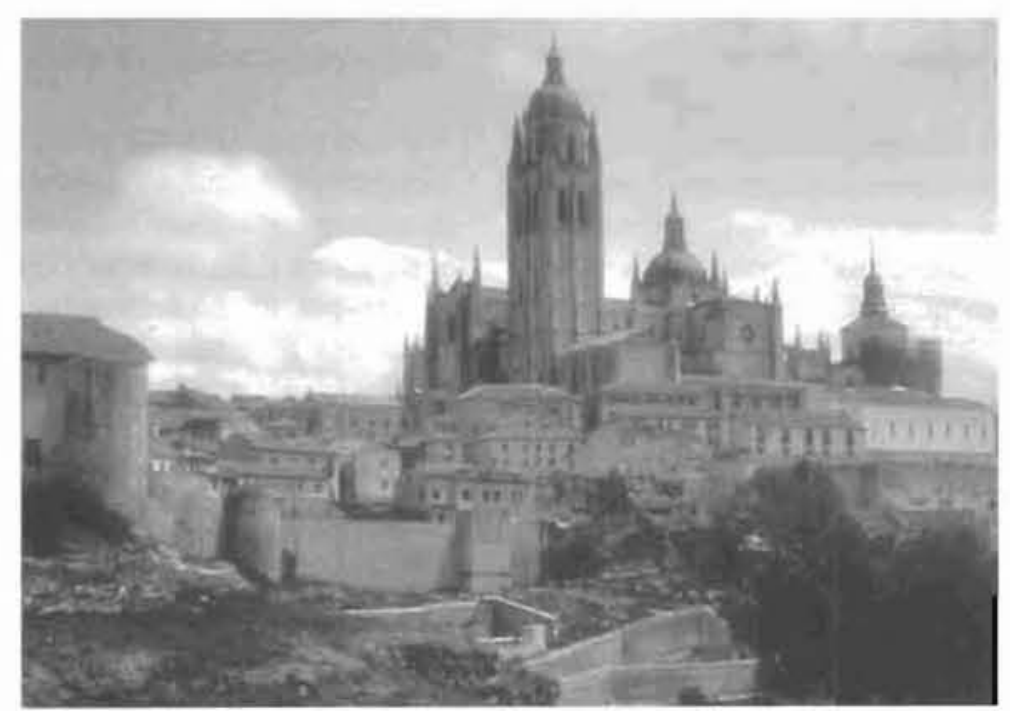

"Nos encontramos ante una concepciòn del hábitat del hombre, que debe responder a sus aspiraciones profundas de belleza, de diversidad y de salubridad" (Ängel Ramos).

\section{RESUMEN}

El Plan Verde de Segovia es la puesta en práctica de una metodologia de actuación general y peculiar para defender la sostenibilidad de la ciudad.

El objeto del referido Plan es la recuperación, conservación y mejora de la calidad ecológica y paisajistica de la ciudad y su entorno, a partir de un análisis del medio urbano y periurbano, y sobre la base de una programación fundamentada en la visión integral de los aspectos ambientales.

El presente articulo describe, tanto los pasos dados para la redacción del plan y la subsiguiente elaboración de una propuesta general de actuación, como el desarrollo de esta última.

Se expresan también los resultados de la revisión y evaluación del Plan tras ocho años de ejecución y la estrategia derivada para completar y mejorar el Plan inicial.

\section{SUMMARY}

Segovia's 'Green Plan'is the putting into practice of a methodology for the action, both general and peculiar, in order to defend the town's sustainability.

The aim of the Plan is the recovery, preservation and improvement of the landscape and ecological quality of the town and surroundings, starting from the analysis of the urban and peripheral environment, and on the basis of a programme founded upon the comprehensive understanding of environmental aspects.

This article describes not only the steps taken for the writing of the Plan and the subsequent elaboration of a proposal for general action, but also the development of this action

The results of the revision and evaluation of the Plan after eight years of execution are also explained, as well as the ensuing strategy for the completion and improvement of the initial Plan. 


\section{La ciudad de Segovia}

Segovia es una ciudad prerromana, situada en plena meseta castellana, al pie de la sierra de Guadarrama.

La ciudad se levanta sobre un roquedo excavado y aislado, conformado por dos cursos de agua: el río Eresma y el arroyo Clamores. Ambos cercan la ciudad en un abrazo espontáneo y dulce, que se estrecha y concluye bajo el Alcázar, cuando los dos valles se funden en uno solo.

Estos valles son de suma importancia estratégica, histórica y cultural para la ciudad. Pero además son claves como sustento de los valores ecológicos, paisajísticos y ambientales. Una orla de verdor imprime carácter y originalidad al recinto histórico: la vegetación de los cursos de agua y el arbolado de las laderas que sustentan las murallas hacen que Segovia emerja como un oasis en medio del páramo castellano.

La traza de la ciudad propiamente dicha se configura entre los siglos XV y XVI. Estos siglos coinciden con el auge de la ganadería y de la industria pañera, lo cual tiene una incidencia capital en el tipo de ciudad resultante y en las caracteristicas de su entorno.

Desde la baja Edad Media viene existiendo una clara diferencia entre la ciudad fortificada y los arrabales, hecho éste que tiene sus repercusiones en la manera de ser y de entender la ciudad, asi como de manera especial en los usos de suelo, de su área periurbana.

Las especiales características del patrimonio histórico, paisajistico y natural de la ciudad han generado una serie de declaraciones de protección que ponen de manifiesto su interés y peculiaridad:

- En 1941 se declaran Monumento Histórico Artístico varios conjuntos parciales de la ciudad, así como "las vistas panorámicas que se descubren desde los bellísimos miradores de la plaza del Alcázar y La Canaleja".

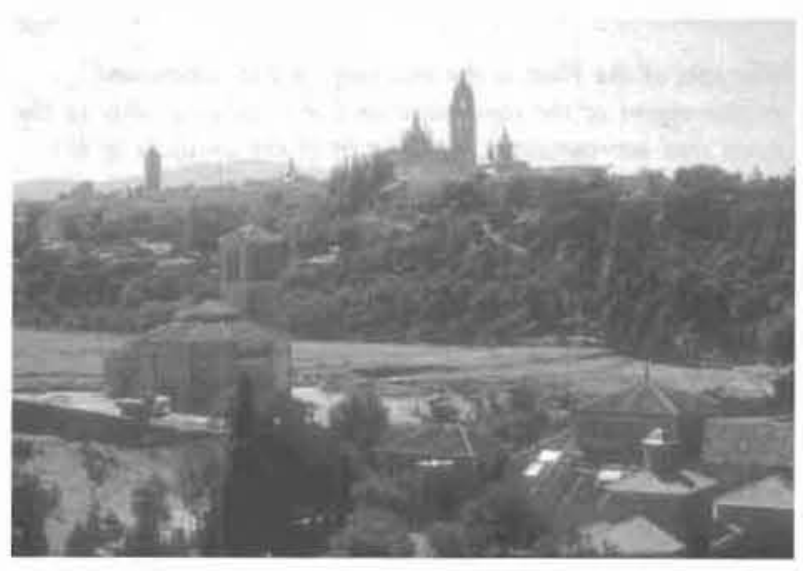

Los valles y su arbolado imprimen carácter y originalidad a Segovia.
- En 1947 se declara "Paraje Pintoresco el conjunto de arbolado y alamedas de la ciudad de Segovia"... "Los alrededores de Segovia, de fama mundial, constituyen una vista panorámica de incomparable belleza..."

- En 1986 Segovia es declarada por la UNESCO "Patrimonio de la Humanidad".

\section{La situación de aquel momento (1990)}

Pese a todo lo expuesto, a finales de la década de los $80 \mathrm{y}$ principios de la de los 90, los aspectos ambientales de la ciudad y su entorno y especialmente los dos valles que la configuran, estaban muy deteriorados: ríos contaminados con vertidos directos, márgenes fluviales abandonadas y con procesos erosivos, huertas olvidadas deteriorándose, espacios solitarios y peligrosos, pérdida progresiva de valores histórico-culturales y tradicionalts, focos de vertidos incontrolados y creciente amenaza urbanística.

Por otra parte afloraba, ya en esos años, un movimiento europeo que primaba los aspectos vinculados a la calidad de vida, la ecología urbana y la visión integral de la ciudad y su entorno. En la misma línea, el cuidado del paisaje urbano-periurbano, la conservación de los valores naturales de la ciudad y sus alrededores, la existencia de zonas verdes, espacios libres,... dejaban de ser consideradas un capricho romántico y se transformaban en una auténtica necesidad.

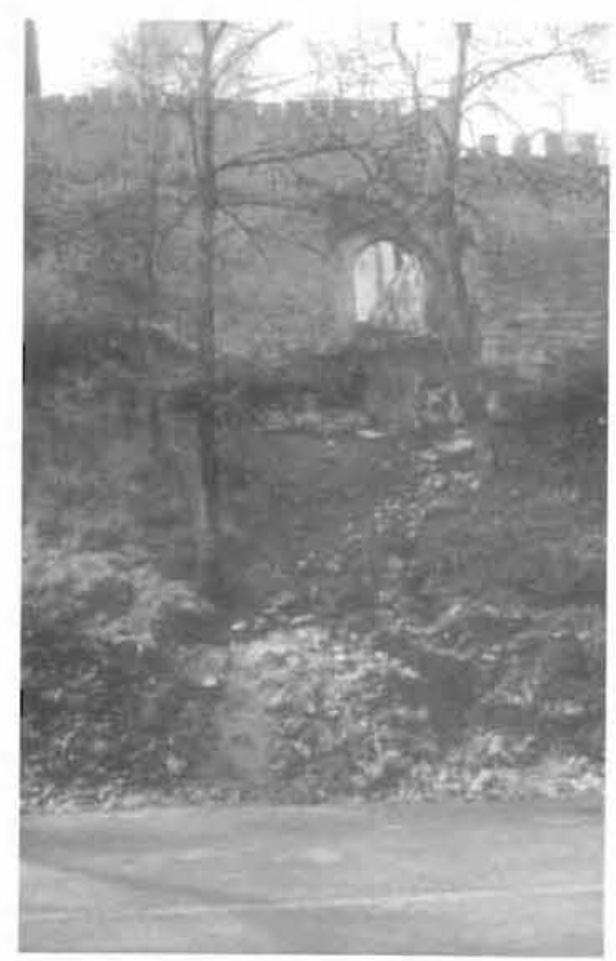

En 1990 era relevante el abandono imperante en el entorno de la ciudad. 
En la línea arriba indicada se pronunciaban el IV Programa de Actuación de la Comunidad Europea", el "Manifiesto Europeo del Medio Ambiente Urbano", la "Campaña Europea para el Renacimiento de la Ciudad", promovida por el Consejo de Europa, la "Conferencia Europea de los Poderes Locales sobre las Ciudades Históricas" y las "Jornadas Hispano Francesas de Agricultura Periurbana", por poner algunos ejemplos.

Incluso el "Convenio para la Salvaguarda del Patrimonio Arquitectónico de Europa" que fue ratificado por el parlamento español en 1989, señalaba en su artículo primero su referencia a los "Sitios" (entendidos éstos como obra combinada de la mano del hombre y de la Naturaleza), haciendo obligatoria la conservación, recuperación y mejora del Medio Natural relacionado con la ciudad.

Se sumaba a ello el anuncio de la entrada en funcionamiento en el Consejo de Europa de un grupo mixto de expertos en paisaje que aunara medio ambiente, entorno monumental y patrimonio.

A todo ello se unía la propuesta que hacía la "Comisión de las Comunidades Europeas" relativa a la necesidad de plantear programas globales de mejora ambiental de la ciudad y su periferia, así como la invitación concreta de elaborar "Planes Verdes" que protegieran y revalorizaran el potencial de los espacios abiertos y del entorno natural de nuestras ciudades.

\section{La gestación del Plan Verde}

Asi se empezaba a gestar un Plan que, apoyado en la metodologia propuesta por la tesis doctoral "Entorno y paisaje de una ciudad histórica. Segovia", tiene como premisas:

- El respeto de la estructura tradicional urbana y periurbana, intentando que la expansión urbana no arrolle la vieja trama urbana, ni sus hitos y monumentos de interés.

- La preservación del paisaje y de las visuales que se contemplan desde la ciudad hacia el exterior $y$, viceversa, vistas que la ciudad ofrece desde el exterior.

- La intención de procurar que las nuevas barriadas sean diseñadas y tratadas como elementos del paisaje, que sean habitables y no frías y desangeladas, que sean legibles y que inviten al intercambio social y no al aislamiento. En este sentido, no se debe olvidar el empleo de un recurso importante cual es el aprovechamiento de la experiencia pasada. Quizás sea interesante recurrir a los modelos de muchas de nuestras viejas ciudades, que han conjugado lo estético con la sensación de acogida.

- La conservación de los usos tradicionales del suelo. Un criterio racional en este sentido nos llevaría al

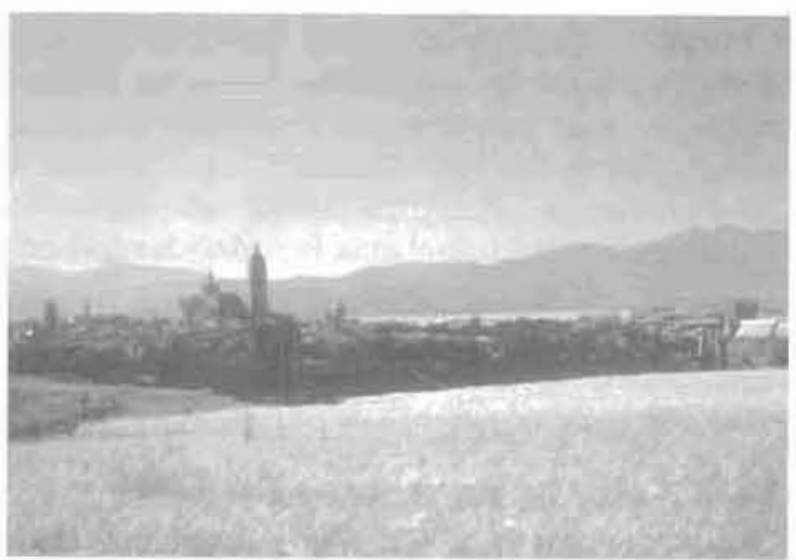

La conservación de la agricultura periurbana es clave para el paisaje de la ciudad.

mantenimiento de un paisaje periurbano vivo, útil y apto para ciertos usos, en el que se conserve la agricultura y la horticultura. Piénsese en la importancia que ambos usos tienen, tanto desde un punto de' vista productivo como paisajístico (marco de calidad apto para el paseo, el descanso, la contemplación,... o como espacio protector y realzador de otros).

- La consideración de que el entorno periurbano es algo intimamente unido a la ciudad, que debe ser cuidado y respetado, entre otras muchas razones por la clara relación existente entre la calidad del entorno, la calidad del área construida y la calidad de vida.

- La protección de los cursos de agua, y ello tanto por su poder para evocar o producir emociones en el ser humano, como por la vegetación y exuberancia que genera el agua, asi como por los valores paisajísticos asociados.

- Reducir al máximo las alteraciones topográficas importantes: cobertura de barrancos, actividades extractivas en lugares de fragilidad visual importante,...

- Restaurar y adecuar las áreas afectadas por los accesos a la ciudad, considerando los aspectos visuales y vigilando el afloramiento inapropiado de naves y construcciones desagradables.

- Potenciar el arbolado en la ciudad, tanto en su interior como en su entorno periurbano. El arbolado, además de poner de relieve el patrimonio construido, es un elemento insustituible para definir y reestructurar los bordes urbanos. Es el intermediario entre el hombre y la naturaleza y, por tanto, es la clave para suavizar la transición de lo urbano a lo rural.

- Potenciar que la ciudad y su entorno sean paseables, conservando, mejorando e incluso creando una trama de caminos peatonales, a ser posible arbolados, que unan la ciudad con el campo. Diseñar paseos que eviten que el tráfico gane la partida al peatón. 
- Primar las premisas del diseño ambiental: el empleo de materiales, colores, volúmenesy formas que predominen en el lugar y pertenezcan al ambiente circundante. Sencillez y fidelidad al entorno deben presidir las intervenciones, constituyéndose en elementos fundamentales de diseño el agua, la piedra y la vegetación.

Sobre la base de todo lo expuesto, el Ayuntamiento toma conciencia de la necesidad de atender estas crecientes demandas sociales, tanto más urgentes cuanto que se trata de patrimonios amenazados por destrucciones irreversibles. Por ello y conscientes de que se trata de un ecosistema urbano con multitud de necesidades y limitaciones sociales, económicas e institucionales, se redacta y aprueba "El Plan Verde de Segovia". Esto pasa en 1991, año en el que el pleno municipal lo reconoció.

\section{Descripción del Plan Verde}

El Plan Verde pretende planificar la conservación, recuperación y mejora del "verde" urbano y periurbano, sobre la base de los aspectos ecológicos, paisajísticos y sociorrecreativos.

El plan realza valores como el capital natural (sistemas hidrológicos, ecológicos, biodiversidad), el paisaje antrópico (valores histórico-artístico-culturales, prácticas tradicionales de cultivo), el fomento del uso recreativoeducativo del entorno (ocio, paseo, educación ambiental) y el aprovechamiento de su potencial como pulmón verde, con generación de sinergias positivas entre lo urbano y lo rural.

Dicho plan propone un programa de actuación que incluye:

- La conservación de las áreas y usos de calidad.

- La recuperación de usos agrarios (huertas, dehesas, praderas)

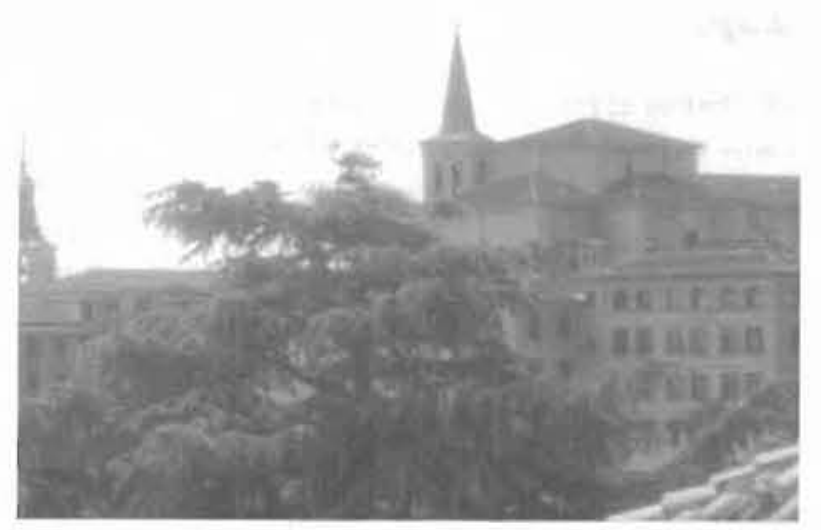

El Plan Verde realza los valores de la Naturaleza en la ciudad.
- La restauración de los aspectos ecológicos y paisajísticos deteriorados, tales como riberas, laderas, arboledas, páramos y lastras.

- La mejora de las visuales de la ciudad y desde la ciudad.

- El saneamiento integral de los cursos de agua.

- La provisión de usos recreativos.

- La adecuación de lugares tradicionales de paseo y estancia.

- El acondicionamiento y remodelación de espacios libres.

- La potenciación del conocimiento integral de la ciudad y su entorno en los aspectos ecológico-paisajísticos y ambientales, fomentando su disfrute.

\section{El proceso seguido}

Es preciso aclarar previamente que en todo momento se ha buscado confeccionar un documento con un sentido de integración, tanto en la realidad urbanística municipal, como en el entomo natural y rural que rodea la ciudad.

El plan se fundamenta en la búsqueda de unas líneas de acción operativas, basadas en la gestión integral, que es la herramienta clave para tratar globalmente el conjunto de problemas que suscita la Planificación y que abarcan los aspectos técnico, económico, social y ecológico.

Lógicamente el punto de partida es la recogida de información, como en cualquier proceso de este tipo.

Se realizó un meticuloso estudio del medio físico: vegetación y usos del suelo, geomorfología, hidrologia, paisaje, etc.

Se hizo un análisis completo del planeamiento municipal existente.

Se recopiló incluso la información literaria existente, pues, en palabras de Chueca Goitia, "no deben perderse de vista, al estudiar las ciudades, las valiosas fuentes que nos ofrece la literatura".

Asimismo, se estudiaron también los aspectos históricoculturales.

- El paso siguiente fue el establecimiento de una serie de objetivos, criterios y restricciones en torno a la conservación y mejora de un cierto carácter antiguo y tradicional y a la provisión de ciertas necesidades nacidas de nuevas circunstancias. Aquí, por ejemplo, se hizo hincapié en el interés de lograr un paisaje periurbano, útil y apto para ciertos usos, en el que se conservaran la agricultura y la horticultura periurbanas. 


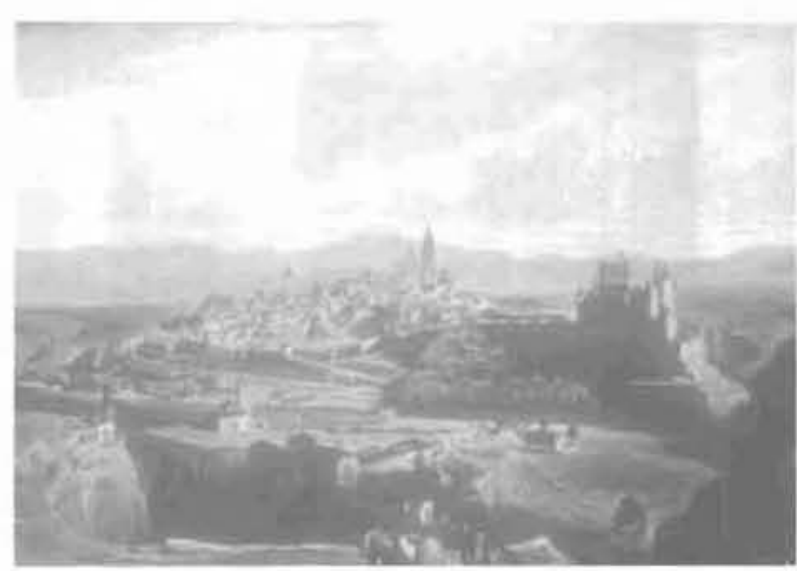

El estudio y consideración de los aspectos histórico-culturales es parte esencial del Plan Verde (grabado de Guesdón).

- A continuación se dividió el territorio en "Unidades Homogéneas de Actuación", tanto por sus rasgos físicos, como porsu significado global para la ciudad, como por su posibilidad de individualización cara a las actuaciones que se habrán de acometer.

- Después se desarrolló un nuevo bloque informativo para la descripción de las distintas unidades encaminada a la actuación, actuación que obviamente entraña la protección centrada en la consideración de aspectos como la calidad, la fragilidad, los impactos existentes y la aptitud oposible destino, uso del suelo, de la unidad. La descripción se completó con una relación de acciones a emprender para su recuperación. Se efectuó también una estimación de los costos que podía entrañar su ejecución.

- Posteriormente se procedió a la caracterización de las unidades. Para ello, de acuerdo con los objetivos y criterios prefijados anteriormente, se elaboró de nuevo la información recogida de modo que resultara operativa. En nuestro caso se hicieron cuatro grupos:

- Vegetación y usos del suelo.

- Singularidades culturales y naturales.

- Aspectos paisajísticos o de calidad del paisaje: Usos del suelo

Singularidades

Incidencia visual

- Potencial de actividades recreativas al aire libre: Aceptación por parte del público

Accesibilidad

Existencia de vistas notables

-Se siguió por la valoración de los distintos tipos existentes dentro de cada uno de estos grupos y, se obtuvo, asi una descripción valorada de las unidades de gestión.
- El último paso de la planificación fue la presentación de las prioridades de acción. Si bien en la ejecución se mezclaron criterios politicos con criterios técnicos y de oportunidad, una primera priorización se efectuó en función de aspectos como: primar las unidades de gestión de mayor calidad y de mayor capacidad recreativa.

\section{Los resultados}

Lo cierto es que ocho años del Plan han transformado la realidad "verde" municipal:

- Las laderas arboladas de las murallas y de los valles se han visto cubiertas con un estrato vegetal acorde con las características del lugar.

- Los paseos periurbanos de alta calidad, que transcurren a media ladera y que conectan la ciudad con el entomo "natural", han sido recuperados y debidamente adecuados

- Las márgenes de los ríos quedaron restauradas y se adecuaron tanto las sendas para su recorrido, como las áreas estanciales próximas a ellos.

- Las laderas no arboladas mejoraron su aspecto.

- Lastras y páramos circundantes se limpiaron de escombros y vertidos en general.

- Las nuevas barriadas iniciaron un proceso de mejora estancial y visual mediante la plantación de arbolado.

- Algunos taludes y espacios verdes de la ciudad al ser debidamente tratados realzaron sus visuales y mejoraron la calidad de los paseos.

- Se transformaron, de manera acorde a las necesidades actuales, muchas de las zonas libres existentes.

- Se inició un proceso de realce y potenciación del arbolado urbano y periurbano, que ha tenido especial relevancia en el nuevo paso dado en relación con el Plan Verde, y que más adelante se describirá ("Plan Especial de Arbolado y Malla Verde").

- Por fin se impulsó un proceso de educación ambiental que ha empezado a dar sus frutos.

La magnitud de los resultados logrados puede plasmarse en los siguientes indicadores cuantitativos, muy significativos si se tiene en cuenta que Segovia dispone solamente de 55.000 habitantes:

- 370.000 metros cuadrados de zonas verdes y espacios naturales recuperados.

- 680.000 metros cuadrados de áreas reforestadas. 

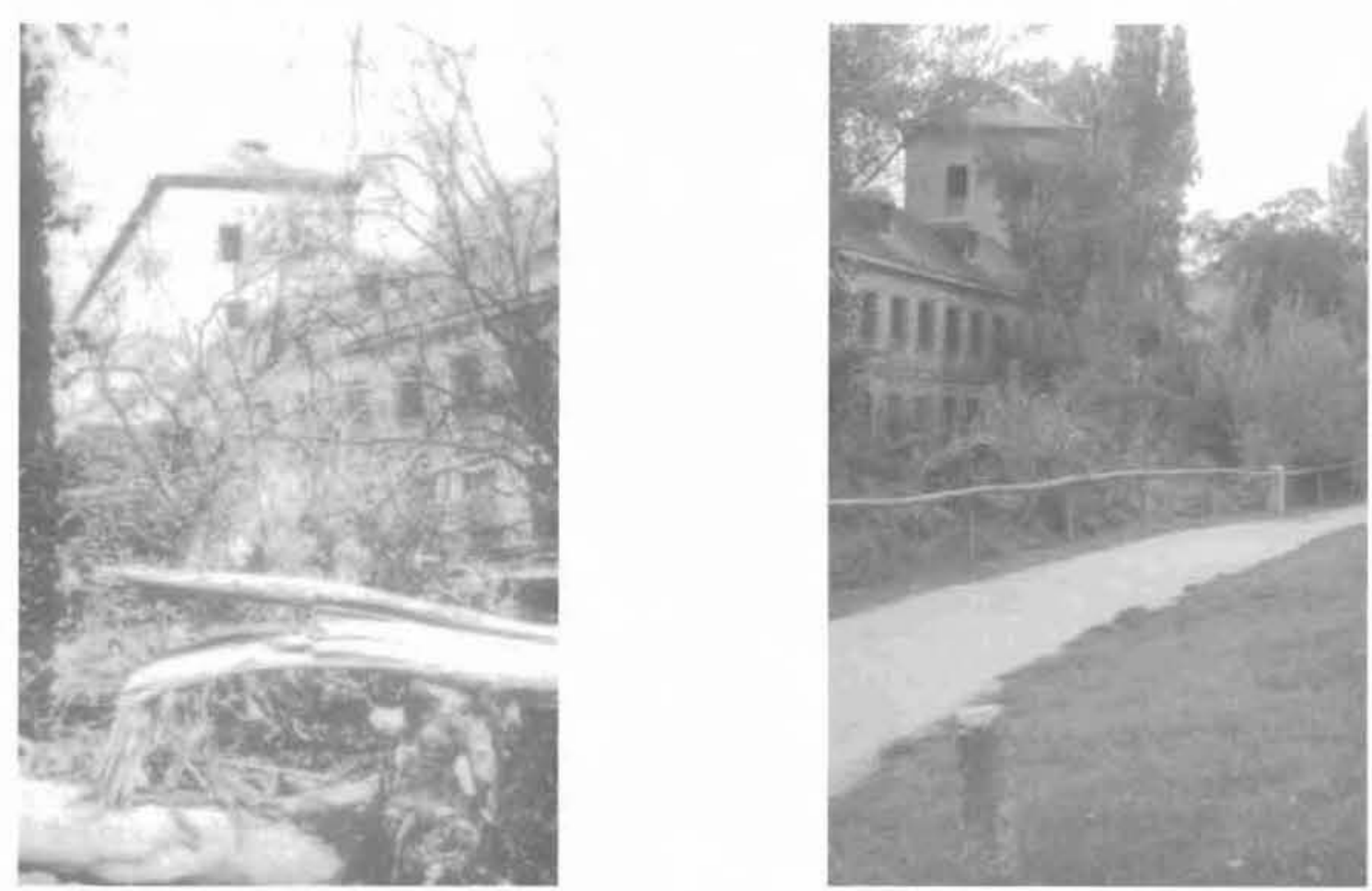

Ayer y hoy de la ribera del liresma por la "Casa de la Moneda". La recuperación de márgenes y los paseos ribereños forman parle de las actuaciones más agradecidas.

. 13.000 metros lineales de paseos para conexión ciudadentorno.

. 5.500 metros lineales de nuevos colectores.

. Depuración de aguas en cantidad de 110.000 habitantes equivalentes (30.000 metros cúbicos por dia)

. Generación de empleo estable para 39 personas.

\section{La revisión del Plan}

Ahora bien, este proceso de recuperación y mejora comentado, aun siendo bueno y válido no es suficiente,

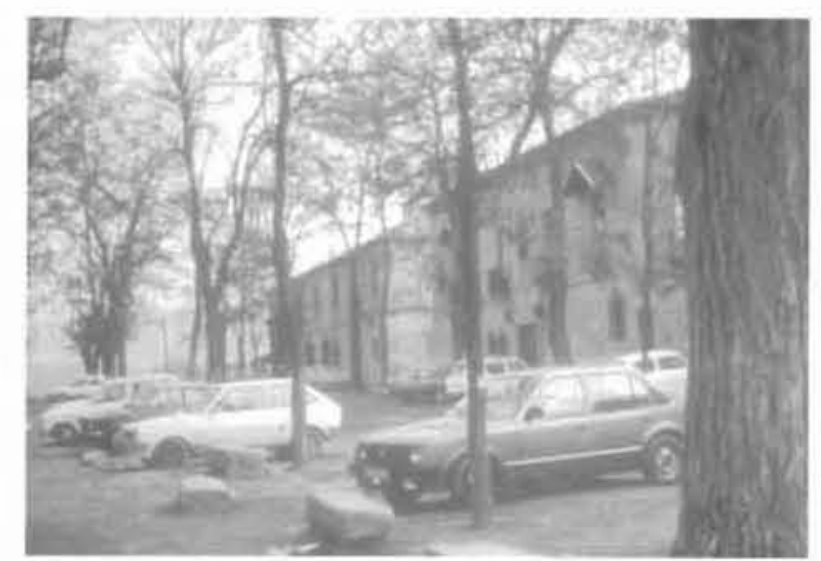

"Tráfico-peaton-zonas verdes": conflicto de intereses a resolver. pues, paralelamente a la recuperación de las zonas referidas, hemos ido constatando problemas y carencias importantes en el ámbito que nos movemos, cual es la salvaguarda del "verde" urbano y del entorno rural periurbano:

- Problemas estructurales urbanísticos, derivados de la supresión de espacios libres, zonas verdes y arbolado por imperativos de un desarrollo urbanístico de base no ecológica.

- Problemas de transformación de estos espacios para construir aparcamientos, facilitar la circulación rodada o favorecer la instalación de otras infraestructuras.

- Falta de conexión entre los distintos barrios a través de una malla verde que garantice el diálogo peatonal entre las distintas partes de la ciudad.

- Necesidad de desarrollar un programa de recuperación visual y ambiental del entorno de los accesos a la ciudad.

- Abandono de la agricultura periurbana, especialmente de las huertas, constatándose, además, la gran dificultad que supone conjugar distintos usos en estos lugares $\mathrm{y}$, a su vez, compatibilizarlos con los aspectos paisajísticos y tradicionales.

- Malas condiciones ambientales urbanas para la vida del arbolado, pieza clave del "verde" urbano, tales como contaminación atmosférica y del terreno, compactación del suelo, pérdida de aireación y de permeabilidad del 
mismo, proliferación de infraestructuras y tuberías por el sustrato, agresiones por obras, etc.

- Falta de una planificación y gestión correctas en las operaciones tocantes al arbolado: mala ubicación, mala elección de especies, podas inadecuadas, etc.

Una propuesta para el futuro: el plan Especial de Arbolado y Malla Verde

Ante la importancia que tienen los aspectos ambientales y paisajísticos en Segovia y ante el conjunto de problemas que se nos plantean y, más concretamente en atención a los especiales valores de la trama verde urbana y periurbana, como parte esencial de la configuración de la ciudad, de su carácter y de su originalidad, vimos la conveniencia de organizar una nueva estrategia, que complementara el Plan inicial y que, más allá del proceso de recuperación y mejora en marcha, garantizara la salvaguarda del capital natural de la ciudad y su entorno a través de una correcta gestión, incluso buscando un soporte legal a esta pretensión.

A continuación se describe el proceso seguido para la redacción del "Plan de Gestión Integral de arbolado y Malla Verde" y del consiguiente Plan Especial de Arbolado y Malla Verde".

Elprimer paso fue la nueva inventariación de toda la malla verde, desde los jardines y plazuelas, hasta el ámbito rural periurbano, y desde el nivel general hasta precisar el número de árboles, su ubicación y caracteristicas, pasando por un análisis de su problemática de gestión.

Se diseñó una potente aplicación informática "al caso" capaz de almacenar todos los datos precisos para la correcta toma de decisiones del día a día y para la continua actualización de la información.

El análisis y diagnóstico de la información nos hizo constatar lo siguiente:

- La importancia del arbolado y de la malla verde a dos niveles: el estético-paisajístico y el ambiental. El arbolado tiene en Segovia una importancia clave, la ciudad está impregnada del "espíritu del árbol", de su majestuosidad, su elegancia y sencillez cautivadoras. Ahora bien, la salvaguarda del arbolado pasa por la defensa enérgica del terreno en el que se asienta o en el que potencialmente puede asentarse en un futuro. Es preciso retomar la idea de malla verde para ser fieles al concepto de sostenibilidad, que empuja a que el árbol, el arbolado, la malla verde se constituyan en elemento integrador, estructurante y organizador de la ciudad.

- La discontinuidad, heterogeneidad y mala distribución de la trama verde, incluso con incongruencias de diseño y disfuncionalidad.
- Problemas para el correcto desarrollo del arbolado por cuestiones inherentes a la incultura arbórea urbana y a la falta de planificación de su gestión.

- La necesidad de generar un cambio en los criterios de planificación urbana y periurbana, tendiendo a una planificación con base ecológica, hacia la sostenibilidad.

- El imperativo de reequilibrar la ciudad en cuanto a zonas verdes, buscando soluciones al problema de las conexiones y de la creación de nuevas zonas verdes.

- Generar un compromiso municipal con el arbolado.

- Llegar a una sistematización racional de la gestión de la malla verde en general y del arbolado en particular.

- Hacer hincapié en la concienciación y la educación de la población en relación con estos valores de sostenibilidad, fomentando la participación.

Para lograr todo lo referido, nos pareció imprescindible dar un soporte legal a todas estas consideraciones. Lo más viable y operativo era apoyarnos en el Plan General de Ordenación Urbana vigente y elaborar un Plan Especial de Arbolado y Malla Verde, con soporte en el mencionado Plan General y que cubriera el vacio, las indeterminaciones e inconcreciones existentes; desarrollando, completando, matizando y perfilando la planificación y ordenación de estos espacios especificos en las delimitaciones e imposiciones del referido Plan General. Asi se justifica la conveniencia de transformar la idea inicial de realizar un Plan de Gestión Integral de Arbolado y Malla Verde en la elaboración de un Plan Especial, como garantía de la protección, conservación y mejora no sólo del arbolado, sino también de la Malla Verde como base fisica y ecológica que lo soporta o que puede soportarlo, convirtiéndose así en instrumento clave para la defensa $\mathrm{y}$ fomento del arbolado $\mathrm{y}$ del medio físico urbano $\mathrm{y}$

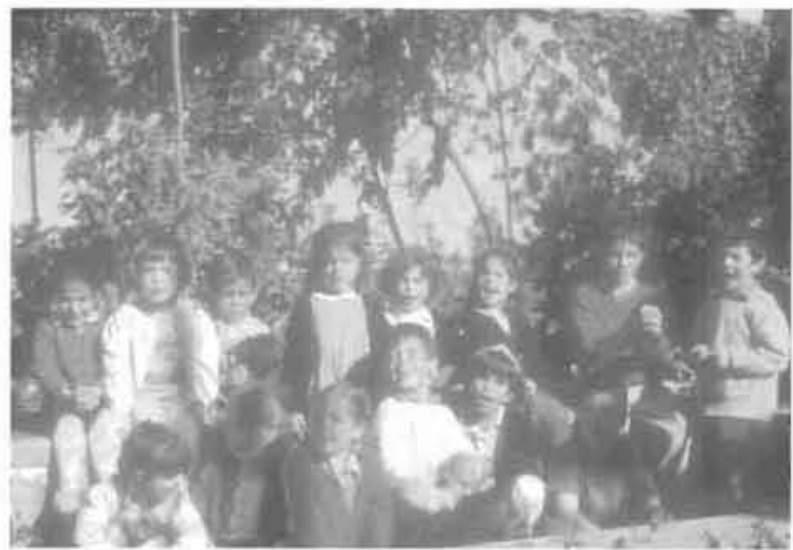

Educación y participación ambiental: esperanza para el futuro. 
periurbano, en coordinación con el planeamiento existente $y$ en uso de las potestades reglamentarias que las leyes otorgan al Ayuntamiento.

El Plan Especial de Arbolado y Malla Verde es, pues, el instrumento jurídico para dar forma a todo el Plan de Gestión Integral del Arbolado y de la Malla Verde. En él se declara el árbol como elemento de interés público y, por tanto, protegido. Dicho plan, aunque está elaborado técnicamente, tiene aún pendiente su tramitación administrativa, lo cual no es obstáculo para que se explique su contenido y metodología, que siguen siendo igualmente válidos.

Este Plan se apoya en la creación de la Malla Verde, como figura representativa del Sistema de Espacios Libres y Suelo Rural Periurbano de la ciudad. Dicha Malia Verde, cuyo hilo conductor ha de ser el Sistema de Arbolado Urbano, se respalda y articula en el planeamiento vigente $y$, a su vez, se vertebra a través de espacios que responden a distintas tipologías debidamente clasificadas.

\section{Descripción del Plan Especial}

A continuación se comentan sucintamente los documentos principales que integran el plan:

Las ordenanzas constituyen el texto normativo del Plan Especial. En ellas se concretan sus objetivos y se regula todo lo relativo al arbolado y a su soporte territorial, presente o potencial. Es decir, aquí se genera el marco legal, es el documento que eleva a rango normativo todos los instrumentos de carácter técnico encaminados a los propósitos antes mencionados.

En las ordenanzas se definen también los instrumentos de intervención, control y ejecución, así como las infracciones yel régimen disciplinario, otorgando, asimismo, el carácter de órgano colegiado al Consejo Asesor de Arbolado, que es un vehículo de participación ciudadana constituido

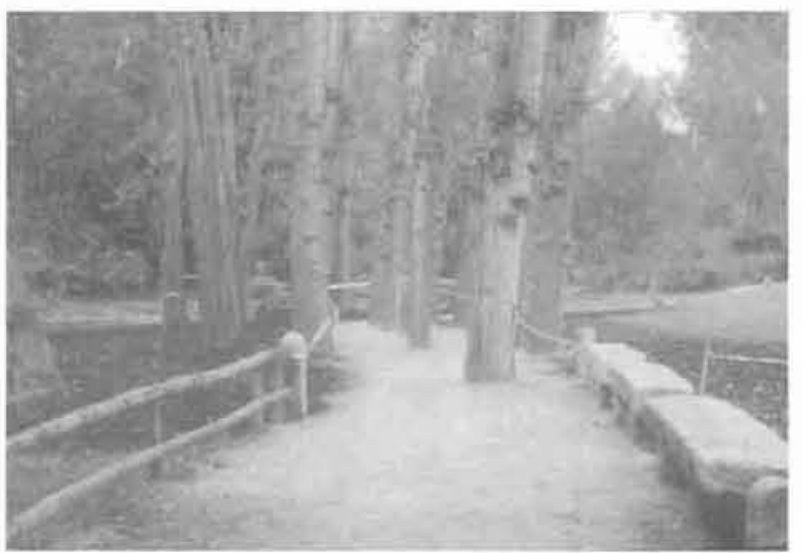

El Plan Director de Arbolado se encarga de la concreción, mantenimiento $y$ desarrollo de la Malla Verde. para el asesoramiento, la propuesta y el control del cumplimiento de los objetivos y directrices del Plan Especial y del Plan Director de Arbolado que luego se comentará.

Se señalan, por su relevancia, las Normas y Especificaciones Técnicas como uno de los documentos constitutivos de las Ordenanzas, pues aportan unos criterios para el diseño, la implantación, la formación y el mantenimiento del arbolado y de ios espacios arbolados o arbolables en el futuro.

El Plan Director de Arbolado es el instrumento de gestión, el brazo ejecutor, definido por las Ordenanzas, con el fin de llegar al estado óptimo previsto para la malla verde. A tal fin, dicho Plan describe la acciones necesarias distribuidas en el tiempo, los medios precisos y su aplicación, así como la forma de racionalizary rentabilizar las inversiones municipales. Es decir, el Plan Director de Arbolado se encarga de la concreción, mantenimiento y desarrollo de la Malla Verde.

El Plan Director parte del inventario anteriormente referido, a partir del cual se realiza una clasificación de las tipologias de los diferentes espacios a efectos de:

- Definir los usos y funciones específicos que eviten el uso indiscriminado y logren que la malla verde ofrezca un abanico diversificado de posibilidades para la población.

- Concretar tanto las actuaciones y dotaciones precisas para cada tipología y, concretamente, para cada zona, como el mantenimiento necesario.

Por otra parte, el referido Plan Director prevé la elaboración de medidas de fomento, divulgación y sensibilización y participación ciudadana e, incluso, directrices en cuanto a formación del Consejo Asesor, a la organización de los medios humanos y, también, a la elaboración de prioridades y programas de actuación.

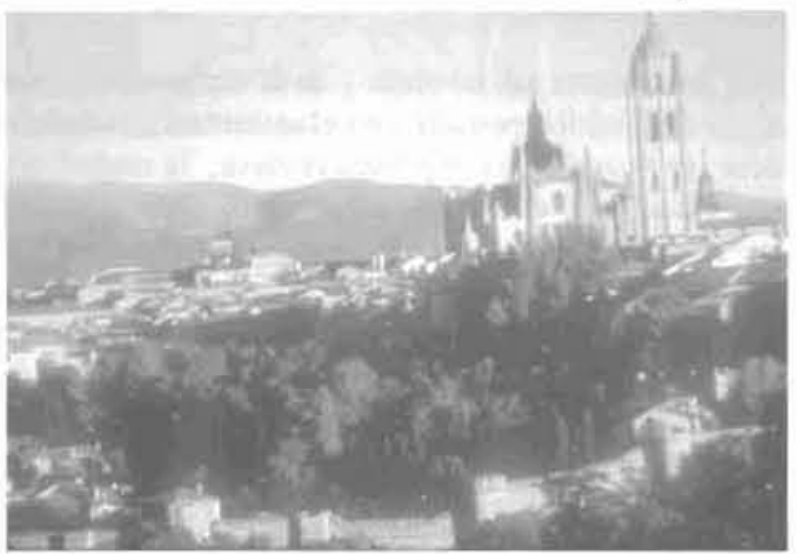

Hacia una planificación con base ecológica, una planificación para la sostenibilidad. 


\section{Conclusión}

En definitiva, lo que se pretende es que desde la realidad existente se genere un proceso de recuperación, potenciación y mejora del "verde" urbano-periurbano tal que, desde el árbol hasta el entorno rural circundante, pasando por los espacios libres en general y las zonas verdesen particular, se constituyan globalmente, en bloque, en la "piedra de toque" de la deseable planificación con base ecológica de la ciudad, de la que la Malla Verde es su soporte físico, ecológico y paisajístico, contribuyendo asi, de forma determinante, a la aspirada sostenibilidad urbana.

Con el presente artículo se espera que los criterios, ideas y planteamientos aquí expuestos sean útiles y aplicables al complejo mundo de las ciudades, más allá del reducido ámbito de Segovia, y en sintonía con la actual corriente hacia la sostenibilidad.

\section{BIBLIOGRAFÍA}

(1) Yoldi, L. (1990): Entorno y paisaje de una ciudad histórica Segovia. Caminos para su conservación.

(2) Arroyo, F,; Esteban, V ; Iguiñiz, G.; Marcos, M.; TECNIGRAL. S.L.; Yoldi, L. (1998). Del árbol a la ciudad sostenible

(3) Ramos, A. (1991): Planeamiento, diseño y gestión de espacios libres urbanos. Seminario Hispano-Portugués sobre jardines y espacios abiertos. Programa MAB (UNESCO), pág. 81-82.

(4) Salvador, P.J. (1993) Diseño y paisaje en el entorno de las ciudades. V Jornadas sobreel paisaje. Segovia, 1992, pp 123-1 28.

(5) Navés, F. (1993) El Plan Paisajistico Integral en el entorno de las ciudades. En V Jornadas sobre el paisaje. Segovia, 1992, pp 139. 147.

(6) Abella, J. A. \& Yoldy, L. (1993). Segovia: Ecologia y Paisaje Guia para una comprensión integral de la ciudad. 